\title{
Libraries across Land and Sea: Academic Library Services on International Branch Campuses
}

\section{Harriett Green}

This preliminary study explores how library services are offered at the international branch campuses of U.S. institutions of higher education, including librarians' experiences, challenges faced, and collaborations with the home U.S. institutions. The data from a Web survey distributed to international branch campus librarians, a conducted interview, and statistical data are presented. The small sample survey data are analyzed qualitatively, suggesting insights on how librarians are embedded in student instruction and staff training and how libraries play an important role in the establishment of international branch campuses. A larger study is strongly suggested to gain more concrete inferences, and the article discusses the role of U.S. academic libraries in the globalization initiatives of their home institutions.

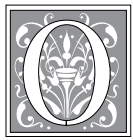

ver the past few decades, U.S. institutions of higher education have stepped out onto the global stage to extend the reach of their institutions and export their resources abroad: they have established partnerships with international higher education institutions to offer degree-granting programs, and they have founded branch campuses in international locations in increasing numbers. Branch campuses are a particularly significant investment as they cement a physical presence of the institution, and most of these branch campuses offer research library services in diverse forms and models.

This study is an exploratory inquiry into how library reference and research services are offered at these branch campuses through physical and virtual academic library services. The author surveyed a selection of librarians who worked at international branch campuses of U.S.-based institutions of higher education though an online survey and an interview. The resulting data from the small but rich survey sample hint at preliminary insights into the branch campuses' services compared to main campus library services, their experiences working abroad with an international population, and the role of libraries in universities' branch campus initiatives. This study seeks to examine and offer speculative insights on the role of U.S. academic libraries in the globalization initiatives of their home institutions as

Harriett Green is English and Digital Humanities Librarian and Assistant Professor of Library Administration at the University of Illinois at Urbana-Champaign; e-mail: green19@illinois.edu. (C) 2013 Harriett Green, Attribution-NonCommercial (http://creativecommons.org/licenses/by-nc/3.0/) CC BY-NC 
well as in the expanding field of transnational education.

\section{Literature Review}

There is a significant body of literature that enables us to understand the internationalization of U.S. higher education institutions and the exportation of educational services abroad. This literature provides important context for understanding how libraries have been and continue to be involved in the global expansion of U.S. higher education.

\section{Literature Review: History of Transnational Education}

Jane Knight defines internationalization as "the process of integrating an international, intercultural or global dimension into the purpose, functions or delivery of post-secondary education." ${ }^{11}$ Among the myriad internationalization initiatives are U.S. higher education programs launched abroad in the form of branch campuses in foreign countries and joint degree programs with foreign institutions. These programs are known collectively as cross-border or transnational education, which is defined "as all types of higher education study programmes or educational services (including those of distance education) in which the learners are located in a country different from where the awarding institution is based." ${ }^{2}$

The modern movement to create international campuses emerged in the 1980s, most prominently in Japan where three branch campuses were founded out of the 1986 U.S.-Japan Committee for Trade Expansion: the now-defunct campuses of Southern Illinois University at Carbondale in Niigata, Texas A\&M-Koriyama, and Minnesota State University-Akita. ${ }^{3}$ Despite the short-lived existences of these campuses, American universities launched branch campuses and collaborative credit-bearing programs with foreign institutions worldwide in the following decades, including Temple University Japan; the University of Chicago's Booth School of Business Executive
MBA London and Asia programs; the Stanford University-National University of Singapore Executive Program in International Management; and Texas A\&M's University Center in Mexico. ${ }^{4}$ Branch campuses also spread across in the Middle East region, including Qatar's Education City complex with Cornell, Carnegie Mellon, Georgetown, Texas A\&M, and Northwestern universities; and the NYU Abu Dhabi campus. There are also active plans by higher education institutions for future campuses, including recently formed partnerships by Yale with the National University of Singapore and two institutions in India; and Auburn University's engineering campus at Shanghai University in China. ${ }^{5}$ Overall, U.S. institutions are among the highest numbers of participants in international degree programs: A 2011 report by the Institute of International Education reported that, in their 2011 survey of 245 institutions from 28 countries, U.S. institutions had the highest number of double-degree programs, in which two degree certificates are awarded from the U.S. institution and partner foreign institution. ${ }^{6}$ U.S. institutions also were among the top three countries with dual-degree programs, where one degree is awarded jointly from both the U.S. and foreign institutions; across all types of programs, English was by far the dominant language in which programs were conducted. ${ }^{7}$

The variance in the transnational programs is often a matter of investment and resources: branch campuses prominently raise a university's profile abroad but require significant investment in infrastructure and human resources. Steve Hirschfeld and Natasha Baker also argue in a 2010 Chronicle of Higher Education essay that institutions must balance the double weight of complying with legal and cultural strictures from both the United States and from the countries where they establish their branch campuses and international programs. They note that universities "must anticipate that conflicts may arise between these laws and 
customs and the institutions' own policies and procedures." 8 Collaborative "franchising" partnerships between U.S. and foreign universities require negotiations between institutions but are economically efficient in the shared distribution of academic and physical resources, also forming the foundation for strategic alliances for future academic, technological, and research objectives. ${ }^{9}$

Another rapidly growing factor in transnational education are U.S.-based for-profit education corporations that include Kaplan; the Apollo Group, which owns the University of Phoenix; DeVry; the Career Education Corporation; and Laureate Education, which owns the Universidad Interamericana campuses in Costa Rica and Panama as well as parts of Universidad Europa de Madrid in Spain. ${ }^{10}$ Jane Knight notes that "it is expected that as the trade liberalization of services increases, so will the numbers of public for-profit companies as well as private for-profit companies."11 The presence of for-profit companies reinforces the stark fact that lies behind the entire transnational education movement: Through the increasingly dominant lens of commercial trade, education is now viewed today as a private good rather than a public responsibility.

According to the Office of the U.S. Trade Representative 2010 annual report, education was the United States' third largest export in 2009 at twenty billion dollars, trailing only the business, professional, and technical services sector and financial services sector, respectively. ${ }^{12}$ Ben Wildavsky notes in his 2010 book The Great Brain Race that the concepts of academic mobility and the research university are being redefined as "more than ever before, the Western research university is being replicated around the world by societies that have realized that the road to economic success runs through college campuses."13

Education has steadily risen over the last two decades to become one of the United States' most viable trade com- modities today and its value is in the scholarship and information services it provides. ${ }^{14}$ Philip G. Altbach and Jane Knight note that knowledge industries such as higher education are a major focus of investment in today's global market, which reflects the "emergence of the 'knowledge society,' the rise of the service sector, and the dependence of many societies on knowledge products and highly educated personnel for economic growth."15 In this knowledge society, scholarship and research are critical, and the markets recognize that both are held in abundance by universities and their libraries.

In recognition of its rapidly growing economic importance, education is one of the twelve service sectors officially designated in the World Trade Organization's General Agreement of Trade Services (GATS), an international trade agreement founded in 1995 among the 145 members of the World Trade Organization. ${ }^{16}$ GATS designates four subcategories of educational services: Cross-Border Supply, which includes distance learning and virtual universities; Consumption Abroad, which includes students studying abroad; Commercial Presence, which is a branch campus established by an institution of higher education or a partnership between two institutions of different countries to offer educational services within a foreign country; and Presence of Natural Persons, which consists of faculty or other university staff providing educational services in a foreign country. ${ }^{17}$ Of these, Commercial Presence services have grown the most in recent decades, as they have produced the largest economic benefits for universities.

Hans de Wit notes that, of his four "rationales" for internationalization, economics is the most dominant reason. ${ }^{18}$ The rapid emergence of education as a tradable commodity presents universities with a new stream of financial revenue through tuition fees, also enabling universities to promote economic growth in the United States and the countries 
they serve..$^{19}$ Politics is another factor in transnational education, as universities trade information services and provide educational aid to nations that do not have enough capacity to meet the educational needs of their citizenry. ${ }^{20}$

The internationalization of universities also is motivated by "providing an international dimension to ... international academic standards," which are a hotly debated issue in transnational higher education. ${ }^{21}$ Strong accreditation standards are essential to ensuring the academic effectiveness and economic value of transnational education services, and the libraries play a major role.

A key challenge for transnational education initiatives is to ensure that their curricula and awarded degrees will be recognized and accepted by institutions and businesses around the world. Yet the issue of accreditation is at least partly rooted in the complex relation between globalization and transnational education: Altbach and Knight define globalization as "the economic, political, and societal forces pushing 21st-century higher education toward greater international involvement." 22 The result of this drive toward internationalization is a "borderless higher education market" marked by "an erosion of the national regulatory and policy frameworks in which universities are embedded." ${ }^{23}$ As such, these policy frameworks translate across borders in varied ways.

The United Nations Educational, Scientific and Cultural Organization (UNESCO) manages international accreditation panels, such as the European Group on Academic Assessment and African Association of Universities, and coordinates multicountry agreements that recognize degrees earned abroad, such as the 1997 Lisbon Recognition Convention. ${ }^{24}$ In the United States, the federally recognized regional accreditation associations are mandated by law to monitor the international branch campuses of American universities and joint international programs in which 50 percent or more of a degree program is offered by the school. ${ }^{25}$ To reinforce this mandate, the Council on Postsecondary Accreditation, the membership organization for accrediting agencies, published the Principles of Good Practice in Overseas International Education Programs for Non-U.S. Nationals in 1990, and it was quickly adopted by accrediting bodies around the world. ${ }^{26}$ And the most recent significant development in transnational education accreditation is the Bologna Process, led by the European Network for Quality Assurance in Higher Education. ${ }^{27}$

But despite these significant steps of progress in transnational education quality assessment, the accreditation of transnational education programs is still a predominantly piecemeal process, marked by misunderstandings, tangled bureaucracy, and an uncertainty over how many transnational education programs actually exist in total. ${ }^{28}$ But among existing accrediting standards, one universal criterion of quality is the quality of library and information services; and, in transnational education programs, the library is a critical bridge between the students and faculty, with the information needed to sustain the academic endeavors of the program.

\section{Literature Review: International Education and Libraries}

The current literature on library services for international patrons and sites ranges in scope. Reference and library services to international students on institutions' home campuses has been extensively examined in recent decades: Mary Beth Allen's 1993 study examined international students' use patterns in academic libraries; and, in their 2001 article, Baron and Strout-Dapaz propose a set of pedagogical methods and information literacy standards customized for international students. ${ }^{29}$ In a 2010 study, Knight, Hight, and Polfer examined the library usage of international students at three different types of U.S. college campuses, and they noted that a "lack of knowledge about the library, perceptions of need, and distance 
are obstacles to library use, rather than the anticipated response of cultural barriers." ${ }^{30}$ However, Hilary Hughes noted, in a 2010 study of international students in Australian libraries, that "it seems important to not just consider what students apparently know about the library or how they use it, but also to develop understandings about their perceptions (and misconceptions) about libraries and librarians." 31 Ann Curry and Deborah Copeman examined the effectiveness and quality of reference interactions between librarians and international students in a 2005 study, and Zhixian Yi analyzed how international students characterized their information needs. ${ }^{32}$ A number of studies discuss outreach services to international students, including 2009 studies by Emily Love and by Puente, Gray, and Agnew, as well as a 2008 study by Bardeen and Norberg.

Another aspect of international library services is the range of services provided to study-abroad students, and extensive studies have been conducted on this topic. In a 2009 article, Virginia Connell discussed the history of study-abroad programs and the need for library access and services, and Laurie Kutner discusses in her 2009 College and Research Libraries article how study-abroad students use their home institutions' libraries in their studies. ${ }^{33}$ Specific model services also exist: Zhonghong Wang and Paul Tremblay's 2010 article discussed the variety of library services provided to Long Island University's Global College degree program; and, in a 2009 study, Alica C. White, Yunshan Ye, and Margaret Guccione examined the information needs of international students and the liaison work for the study-abroad programs at Dickinson College and Goucher College. ${ }^{34}$ These and other articles lend insight into the various ways that libraries extend their resources to patrons abroad.

Branch campus library services combine facets of working with international students and providing library services for distance education programs, but limited studies have been published thus far on such work. In a 2002 study, Suzanne Gyeszly examined the interlending services between the Texas A\&M and Texas A\&M at Qatar campus libraries and also conducted a 2010 comparative analysis of the collection development and circulation services of the six university libraries in Qatar's Education City. ${ }^{35}$ Gyeszly and Matthew Ismail analyzed the collection development policies at the American University of Sharjah, including how the collection was carefully built to serve the needs of the students at the American University of Sharjah. ${ }^{36}$ Charles Gilreath also examined the collection development of the university library at Texas A\&M at Qatar, in which he explored how the Texas A\&M at Qatar Library built a collection of digital and print resources with a relatively low physical footprint. ${ }^{37}$ Yet there are limited studies on the comprehensive services offered at branch campuses, and how library services for U.S. research libraries are provided when immersed within an international location and its wholly different cultural operations.

\section{Methodology}

A Web survey was distributed to forty librarians and library staff at seventeen international branch campuses of U.S. institutions of higher education, with the campuses located in Qatar, Dubai, France, Singapore, Hong Kong, the United Kingdom, and Japan. The eligibility criteria for the surveyed branch campuses was strictly limited to branch campuses of U.S. institutions of higher education; they did not include American-style institutions located abroad (such as The American University in Cairo). The campuses were identified through the author's research in library and higher education literature, as well as general Web searching. The subjects then were identified though the online staff directories of the eligible international branch campuses and their home U.S. campuses. In a few cases, the subjects were referrals from previously interviewed subjects. 
The Web survey was a compilation of multiple-choice and short-answer questions, and subjects completed it via a secure online form. Subjects answered questions on the type of research and reference services they provided, how their services compared to those at their home institution's main campus, collaborations between their branch campus library and the main library system on home campus, and the challenges and benefits of working at the branch campus library of their institution (see copy of survey in appendix A). Data were also gathered through e-mail correspondence with two campuses, and an interview also was conducted with Steven Witt, former library director of the now-defunct Southern Illinois University-Carbondale at Niigata. Witt answered questions similar to those on the survey (see copy of interview questions in appendix B). Additionally, the author compiled basic statistical data on collections, reference services, and staff about all of the surveyed branch campus libraries from their existing in- formational materials found online and provided by respondents.

The respondents to the Web survey totaled eleven librarians from seven institutions with branch campuses in Qatar, Singapore, and Abu Dhabi. Given the relatively low number of responses, the survey results are interpreted as qualitative data that provide significant observations and insights rather than generalizable quantitative results. But for efficiency of analysis, the survey data were still coded and analyzed using statistical tools in Excel for frequency, mean distribution, and graph analyses. Data from the e-mail correspondences and Witt's interview responses are also included as supporting qualitative data.

\section{Data and Analysis}

To gain an overview of the libraries' structures, the author compiled a basic overview of statistical information about the seventeen branch campus libraries. For collections, all libraries provided access to the electronic resources-ebooks, e-journals, and databases - in the

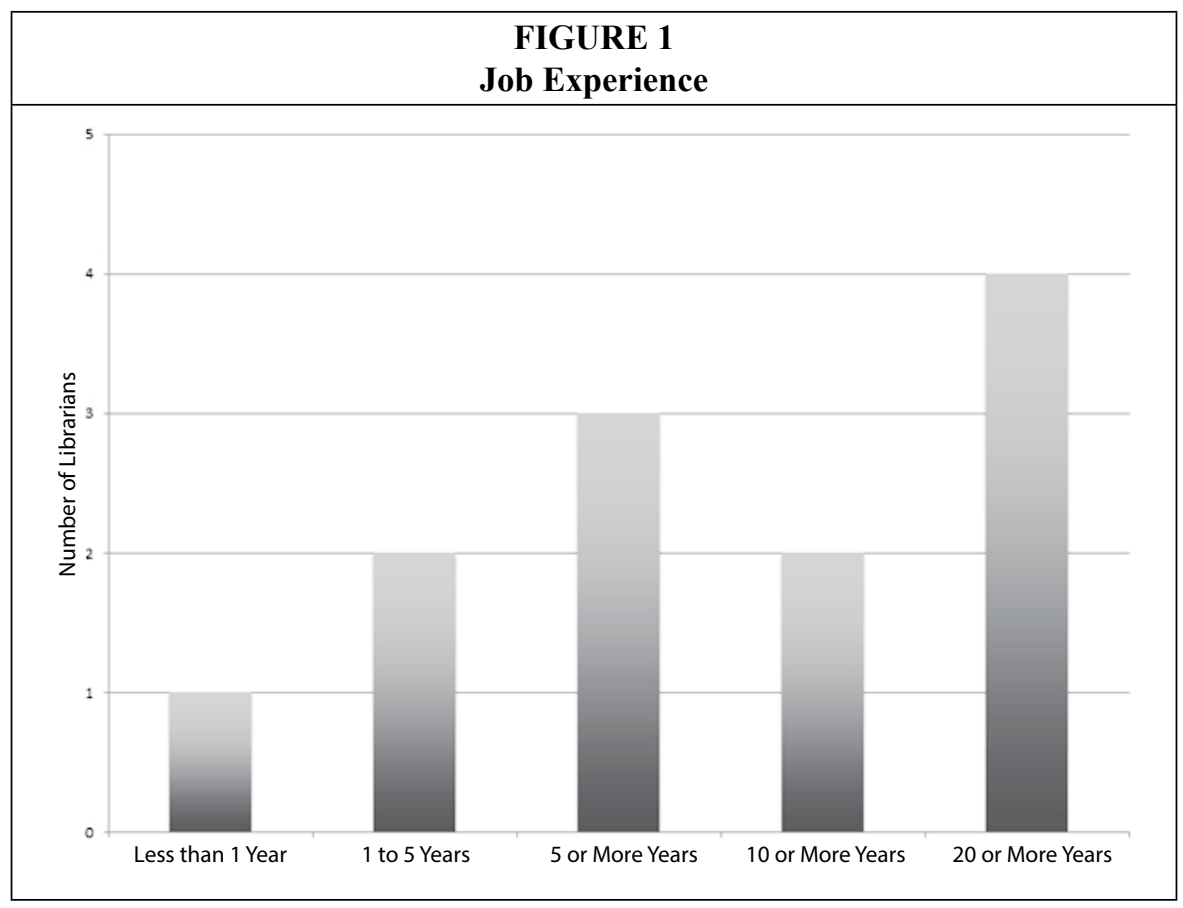


collections of the home campus libraries. But eleven of the branch campus libraries also had established on-site research collections - ranging from approximately 50,000 to over 600,000 items that included media and special collections. All libraries shared the online catalogs with the home institution, and three libraries had an additional separate search limited to their location.

For reference, thirteen libraries provided various types of e-reference services: All thirteen of the libraries offered e-mail reference services, and four of those libraries also conducted electronic chat reference as well. The staffing of the libraries varied as well: Thirteen libraries had zero to five staff persons, while four had ten or more librarians and staff. This overview of the libraries provided a context for the resulting survey responses.

In the survey responses, the distribution between librarians and library administrators was fairly even among the respondents, with six administrators and five librarians. The professional tenure of the subjects was fairly extensive (see figure 1): nine of the eleven respondents had five or more years of work experience, with four respondents having had at least twenty years of work experience.

The reasons given by the subjects for choosing to work at these international branch campuses ranged from "I was looking for a radical change after working in the same job for 14 years" to "I wanted to work overseas as a librarian and it was one of the main reasons I went to graduate school for my MLS" to "Already living overseas." Nine of the librarians applied to their positions, while one was recruited and one librarian worked from his/her home campus as a distance liaison for the international branch campus.

The core part of the survey focused on the subjects' experiences in providing reference and research services at their branch campuses, particularly in comparison to their home institutions on the main campuses in the United States. The aspects they enjoyed about working at their jobs primarily were working with the students and being able to create a new library. One respondent noted that their library was "combining advantages of a large, established organization with flexibility of newer, smaller unit." Another respondent emphasized that "By far, the best part of being over here for me is the motivation level of the students. They are so intent on drinking in every aspect of what they learn. They know that they will be the ones to make the Middle East what it will be in the next 10-20 years and they take their mission seriously. It's also fun to work among so many cultures." The challenges that the librarians faced, however, were more varied in type and aspects of their working environments.

When asked what the biggest challenge was in working at their international campus library, five of the respondents said it was obtaining resources for their library, whether human staff, research materials, or financial funds. One librarian noted, "One of the biggest challenges working in Qatar is finding qualified staff (paraprofessionals). Librarians are hired internationally, but all support staff are hired locally. It is hard to find someone with the strong English language and critical-thinking skills, plus library experience and a strong work ethic." Another respondent noted that they were "coping with much slower deliveries and unexpected hold-ups which create a lot of administrative work locally." Steven Witt explained that accessing materials was the most significant obstacle for his library, noting, "It was difficult to provide access to the resources for those students: book orders were slow and at that point, there was not proxy-type access to journals on servers." ${ }^{38}$ Three respondents indicated that working in a foreign culture and significantly different environment posed challenges. One librarian explained, “Things operate differently here. Getting used to the logistical operations of daily life (both personal and professional) can pose some significant challenges." Another noted, "After working in a fairly 
large university library system in the U.S., there is a sense of isolation in several senses: isolation from developments in librarianship; organizational isolation in a small school where the administration has little understanding of library functions or issues; and physical isolation due to problems with our facilities." The remaining three respondents noted that difficulties had arisen in their efforts to provide services and establish themselves as a library. One respondent said that a constant challenge was "being remembered that we're here and while a microcosm of the main campus, trying to remain included in what is happening at the main campus." Similarly, another respondent noted: "Roles and responsibilities [are] not always clear between home and branch [campuses]."

As such, the interactions between these branch campus libraries and the home campus ranged widely. The level of collaboration was almost equally divided among respondents: Five of the respondents said that they had no collaboration at all with their home campuses' libraries, and six respondents worked with their home campuses' libraries at varying levels. One respondent noted, "It's essential for the librarians here to visit the US campus once per year for about 1 week to discuss problems, solutions and ideas. When the budget permits, we also have 1 or 2 librarians come visit us once a year to get a sense of how we operate. They need to understand that we are a small team and therefore rely on shared knowledge from each other and from the US campus." Other means of communication included video conferencing; in the case of one school, the U.S.-based librarians constantly communicated to the branch campus staff who oversaw the branch library.

The respondents were then asked to compare the resources, the funding, and the organization of personnel and library services at their libraries to those at their home campuses' libraries (see figure 2). For print and electronic resources, six respondents indicated that theirs were worse than the home campus library, while three respondents said they had better resources and two respondents said the quality was the same. Conversely, nine respondents said that their financial support and infrastructure was better than their home campus's library, while two respondents indicated that it was worse. Eight respondents indicated that the organization of personnel and library services was worse at their library, while two said it was the same level and one respondent said the organization was better. As a respondent explained, "Our institution is much smaller than the main campus, so we simply do not have the volume of print materials available that they do. However, we share electronic resources and we are able to provide some that they do not. Our organization is also 'worse' because of our size. We have a small staff and all of us do a little bit of everything. As such, we sometimes don't operate like the 'well-oiled machine' of our home campus library." Steven Witt also explained he was virtually the sole library staffer providing services, noting, "I provided reference services, I was cataloging materials in Japanese and English, and we maintained our own catalog separate from the main campus because we didn't have the same kind of resources. It was 1999 , so the ability to share resources with the main campus wasn't quite there and we didn't have bandwidth to share resources online."39

The primary outcomes for their libraries were similar to their U.S.-based peers: to help students become more information-literate. As one respondent termed it, "As far as the students are concerned, I want to help them become critical consumers of information. That not only involves teaching them how to access the information resources they need, but also how to evaluate those sources for accuracy and reliability. As far as faculty [members] are concerned, I primarily want to connect them with the information that they need for their 


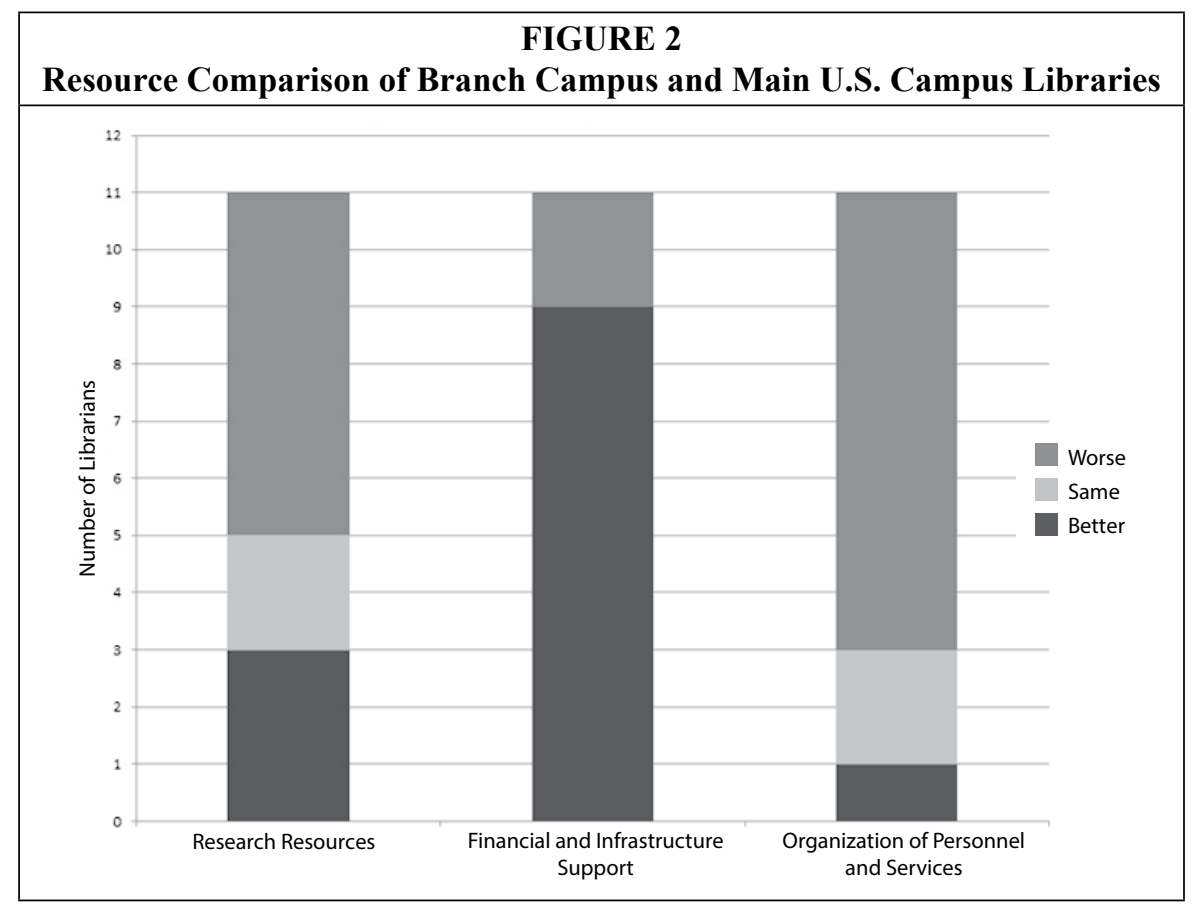

research and instruction. Another respondent focused on the collection, noting that their goal was "to have copies of required texts, suggested alternatives, broad based reference \& study resources, inspirational books, and some selected journals."

Respondents noted that these outcomes were not very different from those at U.S.-based libraries where they had previously worked, although they did note that cultural differences played a role. One respondent explained, "I've had to adapt my methods and expectations to our student body. Most are ESL learners and communicating complex concepts can be challenging. Also cultural differences can pose challenges. For example, teaching using analogies from my culture may not resonate with a percentage of our student body." Another respondent noted, "The main differences are the amount of interaction reference librarians have with the students - much more intensive here, with librarians often working in the classroom or studio; and the EFL factor." But overall, librarians viewed their mission as being akin to the home campus's main library, a goal of serving and educating graduates of the university. As one respondent noted, "We absolutely expect our students to graduate with the same knowledge and skill levels as their US counterparts. In addition, they must be leaders - that is essential in order to play a part in helping the region meet its goals of increasing the intellectual and business-related endeavours." The branch campus libraries view their role as supporting their universities' educational mission, but their work plays out on a highly focused environment that they may be under a more intense spotlight than most U.S. academic libraries.

\section{Discussion}

Several key themes emerged in the survey: One important theme was the increased intensity and embedded interactivity of the librarians' work at international branch campuses. With the opportunities for hands-on work with students and the challenges of creating new libraries from the ground up, librarians at international branch campuses 
create relationships with students and faculty that are critical to the university's overall success. As Dana Beth at Virginia Commonwealth University Qatar noted, "With the lack of other libraries in the area, the school is entirely dependent on us. Our mission: The VCUQatar Library is dedicated to supporting the VCUQatar community by providing high-quality resources, services, and gateways to information to meet the needs of VCUQatar' $s$ instructional, research, and community programs." The respondents emphasized as a whole how the library was an embedded support structure for the instructional programs on their campuses. This preliminary data suggests that, in comparison to the tradition-framed roles of their counterparts at the home institutions, these librarians may have more flexible and immediate opportunities on their branch campuses to become embedded in direct ways into the student instruction as the faculty members develop the disciplinary curricula.

Another critical theme was that the librarians at the international branch campuses deal with stresses and obstacles that extend beyond the usual workplace challenges, as they navigate new cultures and customs that dictate how they interact with the students and faculty. But as another survey respondent declared, "I am so happy living and working in such a multi-cultural place that when I go home to the U.S., I experience culture shock at the amount of 'sameness' that I encounter." The intensely multicultural nature of these libraries is their core attribute that shapes their unique niche in the world of academic libraries.

A third important point to note is how the libraries' provision of services to campus and community users may also depend on the levels of collaboration between the branch campuses and their home institutions' main libraries. While the survey's small sample did not produce a critical mass of data for any definite interpretation, several data points are still worth noting. As the libraries' statistical overview shows, virtually all of the surveyed libraries share online catalogs and electronic resource collections with their home institutions; thus, they share the work of providing core access to many library resources. But when respondents' answers to levels of collaboration were mapped against their responses about the quality of resources, financial support, and organization, there was no significant correlation: three respondents whose libraries collaborated with home campuses indicated that their resources and finances were the same or better as the home institutions, but three respondents with no home institution collaboration also had strong resources and support. And two respondents whose libraries collaborated with the home campuses indicated that their resources were overall worse. But one respondent also stated that, for their branch campus library, "It's essential for the librarians here to visit the US campus once per year for about one week to discuss problems, solutions and ideas. When the budget permits, we also have 1 or 2 librarians come visit us once a year to get a sense of how we operate. They need to understand that we are a small team and therefore rely on shared knowledge from each other and from the U.S. campus." Collaboration is an important factor to consider in assessing the strength of branch campus libraries' services, and a larger survey sample in a future study would produce viable indicators of any existing correlation between collaborative campus relationships and strength of research resource support.

\section{Conclusion}

The role of international branch campus librarians is evolving as the branch campuses establish themselves and strive to expand in their new environments. The results from this initial study reveals that, while most branch campuses are still relatively new and exploratory initiatives, libraries are a consistent and visible component on all campuses that are promoted in variant forms. A future study 
that gathers data from branch campuses' students and faculty members could examine how the libraries may be critical factors in the success of the institutions and the students. Respondents to the survey cited that their libraries serve as communal spaces for students to gather and collaborate; instructional environments where students learn information literacy skills, evidence-based practice, and research expectations; and facilities that provide training and support for both the faculty and international staff and the larger community. One respondent emphasized that "I see the library as having a very important role in the academic success, and retention, of its students. Most of our students are EFL [English as a Foreign Language] with little to no experience with libraries and critical thinking." Libraries thus can play an important role in the growth of these fledgling universities into vibrant educational communities; they are also the source of rare and rich research resources for not only the university but also the surrounding community. These initial data suggest that international branch campus libraries could become more robust and rich in their services through increased collaborations with the primary libraries on the U.S. main campuses.

Another potential area of growth is additional creative outreach programs to students and faculty that could focus on the unique cultural heritages of the patrons as a way to communicate information literacy and techniques of library research. And, perhaps most important, libraries can be a critical signpost of how the institution is educating the students. As Witt noted, "[Y]ou could see through the library that there was a striking difference in the services and resources provided to students at the branch campus - it was sold and marketed as a U.S. campus, but [they] weren't getting the same services and level of support. I think technology today has taken care of some of that with authentication, web based email, proxy servers, etc. But then you look at the qualitative parts of the experience for learning and scholarship." ${ }^{40}$ Other respondents underscored the importance of their libraries to the branch campus's ability to provide quality education, and this fact reinforces the importance of the libraries' abilities to provide resources, services, and support for students and faculty.

This study is an initial exploration of how library services are provided on international branch campuses of U.S. universities, and there are several avenues of exploration for future research. Most important, future studies on this subject will need to recruit a larger and more comprehensive sample of respondents to survey and interview. Areas of focus for future study could include how libraries on branch campuses alter traditional methods of library services to meet cultural practices, methods of collaboration between home and campus libraries, studies of the information literacy programs conducted in the libraries, and the new aspects of international librarianship revealed in these environments of globalized education services.

Boundaries are ultimately becoming only more porous in 21st-century academia, and libraries' ability to adapt may enable them to play a critical role in the globalization of their institutions. 


\section{APPENDIX A. Web Survey}

SURVEY: **Please note that all questions marked with an asterisk must be answered. ${ }^{* *}$ 1. Name:

2. Current institution and library:

3. Position:

*4. How many years have you worked as a librarian and/or library professional?
a. Less than 1 year
b. 1 to 5 years
c. 5 or more years
d. 10 or more years
e. 20 or more years

*5. How and why did you start working at this international branch campus library?

*6. What are the biggest challenges you've experienced while working at an international branch campus library?

*7. What have been the most fulfilling aspects of working at an international branch campus library?

How does your international branch campus library compare to the university library at your institution's main U.S. campus in terms of:

*8. Available research resources in the library, both print and electronic:
a. Better than the university library on the main U.S. campus
b. Same as the university library on the main U.S. campus
c. Worse than the university library on the main U.S. campus

*9. Financial and infrastructure support from the university:
a. Better than the university library on the main U.S. campus
b. Same as the university library on the main U.S. campus
c. Worse than the university library on the main U.S. campus

${ }^{*} 10$. Organization of library personnel and services (Reference services, cataloging and technical services, management of collections, etc.):

a. Better than the university library on the main U.S. campus

b. Same as the university library on the main U.S. campus

c. Worse than the university library on the main U.S. campus

11. If you'd like, write any additional comments for your answers to questions 8-10 here:

*12. What are your primary goals and/or learning outcomes for users at your international branch campus library? (This question is optional if you have not worked at a U.S. academic library.)

${ }^{*} 13$. How do these goals and learning outcomes differ from those at U.S. academic libraries at which you've previously worked? (This question is optional if you have not worked at a U.S. academic library.) 
*14. What do you see as your library's role in the mission and success of the institution's international branch campus?

*15. How does your international branch campus library collaborate with and/or influence the main U.S. campus university library in their strategies for providing reference and research services?

${ }^{*} 16$. Can I follow up with you for clarification and more information, if needed?
a. Yes
b. No

17. If yes, please enter an e-mail address where you can be contacted.

18. Do you have any other comments you'd like to share?

\section{APPENDIX B. Interview Questions}

1. How many years have you worked as a librarian and/or library professional?

2. How and why did you start working at SIU-Carbondale in Niigata's campus library?

3. What were the biggest challenges you experienced while working at SIU-Carbondale in Niigata's campus library?

4. What were the most fulfilling aspects of working there?

5. How did SIU-Carbondale in Niigata's campus library compare to the university library at the main SIU-Carbondale campus in terms of:

a. Available research resources in the library, both print and electronic:

ii. Better than the library on the main U.S. campus

iii. Same as the library on the main U.S. campus

iv. Worse than the library on the main U.S. campus

Explain why.

b. Financial and infrastructure support from the university:

i. Better than the library on the main U.S. campus

ii. Same as the library on the main U.S. campus

iii. Worse than the library on the main U.S. campus

Explain why.

c. Organization of library personnel and services (Reference services, cataloging and technical services, management of collections, etc.):

i. Better than the library on the main U.S. campus

ii. Same as the library on the main U.S. campus

iii. Worse than the library on the main U.S. campus

Explain why. 
6. What were your primary goals and/or learning outcomes for users at SIU-Carbondale in Niigata's campus library?

7. How did these goals and learning outcomes differ from the proposed outcomes at U.S. academic libraries where you've previously worked (if any)?

8. What did you see as your library's role in the mission and success of SIU-Carbondale in Niigata?

9. How did the SIU-Carbondale in Niigata campus library collaborate with the main U.S. campus library in providing reference and research services?

10. How did the SIU-Carbondale in Niigata's campus library influence the main library's reference and research services?

11. Do you have any other comments you'd like to share?

12. Can I follow up with you for clarification and more information, if needed?

\section{Notes}

1. Jane Knight, "Internationalization Remodeled: Definition, Approaches, and Rationales," Journal of Studies in International Education 8 (2004): 11.

2. Andrejs Rauhvargers, "Recognition in the European Region: Response to Recent Challenges from Inside and Outside," in Globalization and the Market in Higher Education: Quality, Accreditation and Qualifications, ed. Stamenka Uvalić-Trumbić (Paris: UNESCO Publishing and Editions Economica, 2002), 78.

3. J. Dorn, "A Case Study: Maintaining and Controlling Academic Standards at U.S. Branch Campuses in Japan," in Ambassadors of U.S. Higher Education: Quality Credit-Bearing Programs Abroad, eds. John Deupree and Marjorie Peace Lenn (New York: College Entrance Examination Board, 1997), 39.

4. Philip G. Altbach and Jane Knight, "The Internationalization of Higher Education: Motivations and Realities," Journal of Studies in International Education 11, no. 3/4 (2007): 298-99.

5. Alexandra Tilsley, "Auburn U. Plans Engineering Campus in China," Chronicle of Higher Education (June 15, 2010), available online at http://chronicle.com/article/Auburn-U-PlansEngineering/65954/ [accessed 6 March 2011]; Zvika Kreiger, "An Academic Building Boom Transforms the Persian Gulf," Chronicle of Higher Education (Mar. 28, 2008), available online at http://chronicle.com/article/An-Academic-Building-Boom/20922/ [accessed 17 February 2011]; Shailaja Neelakantan, "Yale's President Talks about Its Plans for India," Chronicle of Higher Education (Nov. 10, 2010), available online at http://chronicle.com/article/Yales-President-TalksAbout/125273/?sid=at\&utm_source=at\&utm_medium $=$ en [accessed 9 November 2010].

6. Daniel Obst, Matthia Kuder, and Clare Banks, Joint and Double Degree Programs in the Global Context: Report on an International Survey (New York: Institute of International Education, 2011), 9-10.

7. Obst, Kuder, and Banks, Joint and Double Degree Programs in the Global Context, 10, 15.

8. Steve Hirschberger and Natasha Baker, "At the Crossroads: International Programs, Laws, and Cultural Expectations," The Chronicle of Higher Education, Commentary section (Sept. 23, 2010).

9. Knight, "Internationalization Remodeled," 27.

10 Altbach and Knight, "The Internationalization of Higher Education," 299-300.

11. Knight, "Internationalization Remodeled," 23.

12. Office of the United States Trade Representative, 2011 Trade Policy Agenda and 2010 Annual Report of the President of the United States on the Trade Agreements Program (Washington, D.C.: Government Printing Office, 2010): Annex I, pt. III, sec. A.

13. Ben Wildavsky, The Great Brain Race: How Global Universities Are Reshaping the World (Princeton, N.J.: Princeton University Press, 2010), 41.

14. Office of the United States Trade Representative, Annex I, pt. III, sec. A. 
15. Altbach and Knight, "The Internationalization of Higher Education," 290.

16. Jason E. Lane, M. Christopher Brown II, and Matt-Allen Pearcey, "Transnational Campuses: Obstacles and Opportunities for Institutional Research in the Global Education Market," New Directions for Institutional Research, 124 (2004): 58.

17. Lane, Brown, and Pearcey, "Transnational Campuses," 50.

18. Hans De Wit, Internationalization of Higher Education in the United States of America and Europe: A Historical, Comparative, and Conceptual Analysis (Westport, Conn.: Greenwood Press, 2002), 89.

19. De Wit, Internationalization of Higher Education, 89.

20. De Wit, Internationalization of Higher Education, 92.

21. De Wit, Internationalization of Higher Education, 92.

22. Altbach and Knight, "The Internationalization of Higher Education," 291.

23. Dirk Van Damme, "Higher Education in an Age of Globalization," in Globalization and the Market in Higher Education: Quality, Accreditation and Qualifications, ed. Stamenka Uvalić-Trumbić (Paris: UNESCO Publishing and Editions Economica, 2002), 25.

24. John Daniel, "Higher Education: Past, Present, and Future: A View from UNESCO," Higher Education in Europe 28, no. 1 (2003): 22.

25. Steven D. Crow, "Institutional Accreditation and the International Offering of CreditBearing Courses and Degree Programs," in Ambassadors of U.S. Higher Education: Quality CreditBearing Programs Abroad, eds. John Deupree and Marjorie Peace Lenn (New York: College Entrance Examination Board, 1997).

26. Marjorie Peace Lenn, "Higher Education and the Global Market: The Quality Imperative," in John Deupree and Marjorie Peace Lenn, eds., Ambassadors of U.S. Higher Education: Quality Credit-Bearing Programs Abroad (New York: College Entrance Examination Board, 1997), 9.

27. Barbara M. Kehm, "European Education: The Influence of the Bologna Process," Change, May/June 2010: 44-46.

28. As Dirk Van Damme notes, "[W]hat is needed is a truly international and sustainable policy framework for dealing with private and transnational providers, reconciling the interests of national governments, the traditional public higher education sector, for-profit providers, and the needs of the demand side of students and the general public interest" (Van Damme, "Higher Education in an Age of Globalization," 27).

29. Mary Beth Allen, "International Students in Academic Libraries: A User Survey," College $\mathcal{E}$ Research Libraries 54, no. 4 (1993): 323-33; Sara Baron and Alexia Strout-Dapaz, "Communicating and Empowering International Students with a Library Skills Set," Reference Users Review 29, no. 4 (2001): 314-26.

30. Lorrie Knight, Maryann Hight, and Lisa Polfer, "Rethinking the Library for the International Student Community," Reference Services Review 38, no. 4 (2010): 591.

31. Hilary Hughes, "International Students' Experiences of University Libraries and Librarians," Australian Academic and Research Libraries 41, no. 2 (June 2010): 86.

32. Ann Curry and Deborah Copeman, "Reference Service to International Students: A Field Simulation Research Study," Journal of Academic Librarianship 31, no. 5 (2005): 409-20; Zhixian Yi, "International Student Perceptions of Information Needs and Use," Journal of Academic Librarianship 33, no. 6 (2007): 666-73.

33. Virginia Connell, "Getting to Know the Neighbors: Library Support for Study Abroad Programs," Library Philosophy and Practice 11, no. 1 (2009): 1-12; Laurie Kutner, "Think Locally, Act Globally: Understanding Home Institution Library Engagement Among Study-Abroad Students," College $\mathcal{E}$ Research Libraries 70, no. 2 (2009): 158-76.

34. Paul Tremblay and Zhonghong Wang, "We Care-Virtually and In Person: A User-Centered Approach to Assessment, Implementation, and Promotion of Library Resources and Services to a Remote Graduate Campus," Public Services Quarterly 4, no. 3 (2008): 207-32; Alica C. White, Yunshan Ye, and Margaret Guccione, "Study Abroad Students: Designing Library Services to Meet Their Needs," Journal of Library Administration 49 (2009): 187-96.

35. Suzanne Gyeszly, "Document Delivery from Texas to Qatar: An International Intercampus Service," Interlending and Document Supply 37, no. 3 (2009): 116-25; Suzanne Gyeszly, "Qatar Education City's University Libraries: Patrons, Collections and Services," Collection Building 29, no. 3 (2010): 84-90.

36. Suzanne Gyeszly and Matthew Ismail, "American University of Sharjah Library: a Collection Development Project," Collection Building 22, no. 4 (2003): 167-76.

37. Charles Gilreath, "Library Development for Texas A\&M at Qatar: Maximum Access/ Minimum Holdings," Collection Building 25, no. 2 (2006): 52-55.

38. Steven Witt, interview by author, April 8, 2011, Center for Global Studies, University of Illinois at Urbana-Champaign.

39. Witt, interview.

40. Witt, interview. 